\title{
ENTREVISTA COM JOSÉ MARÍA LÓPEZ MAZZ
}

RAFAEL GUEDES MILHEIRA ${ }^{1}$

UFPel

JOSÉ MARÍA LÓPEZ MAZZ é Professor da Universidad de la República de Uruguay. Professor convidado da Universidad Autonoma de Barcelona, Universidad de Sao Paulo e Universidad del Centro de la Provincia de Buenos Aires. Membro da Comision Nacional del Patrimonio Cultural (Ministerio de Educacion y Cultura de Uruguay).

O Professor Lopéz Mazz faz parte de uma geração de arqueólogos que impulsionou e projetou a arqueologia uruguaia a um patamar teórico extremamente refinado. Grande entusiasta de uma arqueologia socialmente significativa, López Mazz tem formado alunos e jovens pesquisadores desde os anos 1980, deixando como principal legado uma arqueologia reflexiva ligada à experimentação de novas técnicas e métodos e ao cotejamento de fontes arqueológicas, etnohistóricas e etnográficas. Atuando como uma das principais vozes em prol da arqueologia dos grupos ameríndios que habitaram o pampa sulamericano, o professor López Mazz tem circulado e difundido suas teorias em vários países da América e do velho mundo. No Brasil, como sócio da Sociedade de Arqueologia Brasileira (SAB) participa frequentemente dos congressos de arqueologia, trazendo sempre discussões atualizadas. Atualmente tem dado uma contribuição importante para a discussão sobre a relação entre os grupos historicamente conhecidos como Charrua e Minuano e a relação destes

\footnotetext{
1 Professor do Bacharelado em Antropologia/Arqueologia e do Programa de Pós-graduação em Antropologia da Universidade Federal de Pelotas. Pesquisador do Laboratório de Ensino e Pesquisa em Antropologia e Arqueologia da Universidade Federal de Pelotas (LEPAARQ-UFPel). E-mail: milheirarafael@gmail.com.
} 
ENTREVISTA COM JOSÉ MARÍA LÓPEZ MAZZ

com os montículos de terra denominados "Cerritos de Índios". Além disso, ampliando seu leque de atuação como arqueólogo, vem atuando junto ao Ministério da Educação e Cultura do Uruguai, coordenando um projeto de recuperação dos desaparecidos da ditadura militar uruguaia, tema este que tem elevado a arqueologia platina, mais uma vez, a uma posição de destaque no cenário internacional. Atuando na área da memória social, seja dos grupos ameríndios do pampa ou dos desaparecidos contemporâneos, López Mazz oxigena frequentemente suas posições teóricas frente a novos contextos de trabalho, buscando sempre abordagens plurais e multivocais em sua arqueologia. Neste sentido: memória social, patrimônio, nacionalismo, sociedades ameríndias, história pré-colonial, arqueologia pós-colonial, multivocalidade, ditadura militar e desaparecidos políticos, arqueologia da paisagem, subjetividades na arqueologia e monumentalidade são temas transversais em sua produção científica, o que demonstra a versatilidade de suas ideias.

1) ¿Cómo usted empezó su carrera académica? ¿Cuál es su formación académica y cómo surgió su interés por la arqueología y la historia de las poblaciones amerindias de la Pampa?

En 1975 inicio estudio de Historia en la Facultad De Humanidades y voy al curso de Prehistoria Americana con el Profesor Antonio Austral. En 1976 se crea la Licenciatura de Antropología con una especialización en Arqueología y otra en Antropología Social. Yo soy egresado de la primera generación en 1980 y siempre procuré el equilibrio, entre una visión social de la arqueología y una preocupación por la materialidad de lo cultural.

En 1983 obtuve un Diploma de Arqueología en la Ecole des Hautes Etudes en Sciences Sociales (Paris) (Maestria) con Niède Guidon/Susana Monzón (1982) y un Doctorado en Estudios de América Latina (Antropología)(1986) en La Sorobona Paris III (IHEAL) co dirigido por Mr. Chonchol e Beyhaut. 
En 1986 me inicié como Asistente de Antropología en la Facultad de Humanidades en la Universidad de la República de Uruguay. Desde entonces desarrollo actividad docente y de investigación en la Cátedra de Técnicas Arqueológicas en la Licenciatura de Antropología (UdelaR). Desde esta posición ha impulsado la línea de trabajo en Arqueología de las Tierras Bajas y en la aplicación de nuevas tecnologías de gestión del patrimonio arqueológico.

En 1986 se creo la Comisión de Rescate Arqueológico de la Cuenca de la Laguna Merín (Ministerio de Educación y Cultura/Universidad de la República) donde se diseñó y ejecutó un gran proyecto nacional que en 1995 tuvo su punto más alto cuando se organizó en Montevideo el Congreso Internacional de Arqueología de las Tierras Bajas con la participación de especialistas internacionales.

Hemos estudiado el poblamiento temprano de la fachada Atlántica de Sudamérica con particular atención al surgimiento de sociedades complejas en la Cuenca de la laguna Merín y el litoral costero y lagunar. En los últimos años trabajo con el historiador Diego Bracco buscando conocer mejor los vínculos entre los grupos Guenoas/Minunanos de los siglos XVIII-XIX y los constructores de cerritos de la Cuenca de la Laguna Merín.

Desde 2005 también coordino un equipo de Antropología Forense en el marco de un Convenio entre la Universidad y la Presidencia de la República para la búsqueda de los detenidos desaparecidos de la dictadura militar (1973-1985).

2) En los últimos años hemos visto una creciente preocupación acerca de la arqueología internacional y su integración social. ¿Cómo usted ve el desempeño de los arqueólogos de América del Sur en el actual panorama socio-político?

Felizmente se ha llegado a un consenso internacional al respecto de la Arqueología como una actividad pública, al servicio del desarrollo sustentable, la economía, la educación y de la República en su conjunto. El desarrollo económico, la intensificación en la explotación de los recursos naturales y las propias necesidades y derechos humanos, crean 
nuevos escenarios donde nuestras disciplinas aportan viejas y nuevas voces a los debates de actualidad.

La Arqueología Sudamericana tiene un compromiso social frente a la educación y frente al ciudadano, que antes no tenía. El desarrollo histórico y social demanda también nuevas narrativas, más justas sobre las configuraciones sociales y culturales sudamericanas, como gustaba decir a Darcy Ribeiro.

Una Antropología y una Arqueología que focaliza nuestra propia diversidad cultural esta hoy, como nunca antes, en la agenda profesional. Hay diferentes escenarios y contratos que demandan excelencia técnica y responsabilidad ética. Es también parte de nuestra devolución social, como sector financiado por los contribuyentes.

3) Hoy, en Brasil, hay un incentivo a la creación de cursos de antropología y arqueología de las universidades públicas. ¿Cómo usted ve el crecimiento de estas dos áreas del conocimiento?

Me parece muy bueno lo que pasa y de gran valor metodológico para los objetivos universitarios a nivel regional. La Arqueología y la Antropología no son más disciplinas de interés lejano y distante de la realidad. El ejercicio profesional y académico de nuestras disciplinas ha sabido estar al servicio de la sociedad actual, democratizando el pasado y la cultura (integrando la diversidad cultural) y tratando el patrimonio cultural como oportunidad histórica para el desarrollo local.

La Arqueología y la Antropología al reconocer la multivocalidad se comprometen técnica y humanamente con los desafíos democráticos de la sociedad de este tiempo. La universidad produce los recursos humanos para que el estado ejecute las diferentes políticas públicas, y ofrece excelencia científica.

Hay antecedentes históricos muy sólidos para el desarrollo de una Antropología y una Arqueología universitaria a nivel regional. La construcción nacional en Brasil y Sudamérica le deben mucho a la Arqueología y la Antropología. Pero estas disciplinas también tuvieron en nuestro continente un banco de pruebas, un gran laboratorio para el debate en ciencias humanas y la diversidad cultural. 
La maduración académica y universitaria de nuestra actividad de investigación, exige más que nunca una presencia en los múltiples escenarios de lo cotidiano y lo regional. Es la gran oportunidad de mostrar cuán aplicadas pueden ser nuestras disciplinas al desarrollo humano.

4) Usted tiene un nombre muy relacionado a su caminada de estudios de los sitios arqueologicos conocidos como "Cerritos", comoras de tierra creadas por el acción del hombre, que ocurren en el territorio uruguayo, argentino y en sur de Brasil. Los llamados "Cerritos de indios" muy estudiados desde los años 1970 en Brasil y Uruguay fueron centro de distintas abordajes teóricas. Ellos fueron tratados, a veces como vestigios del pasado de poblaciones que vivieron en la Pampa, conocidos por la "macro-etnia Charrua-Minuano", otras veces como vestigios de grupos cazadores-recolectores sin relación directa con las poblaciones amerindias históricamente conocidas. En sus últimos trabajos, usted sigue esta linealidad entre los "Cerritos" y los "CharruaMinuano", volviendo a discutir, incluso, el concepto de "macro-etnia Charrua-Minuano". ¿En esta cuestión, me gustaría saber cuál la motivación teórica que se lo llevó a volver a esta linealidad?

En la historiografía Uruguaya hay una separación muy exagerada entre las crónicas del siglo XVII en adelante y la presencia (ausencia) humana prehistórica. Nadie vinculó charrúa minuano con cerritos, pero tampoco nadie negó el vínculo entre charrúa minuano y cerritos. No hay referencia explícita ni en una ni en otra dirección.

Esa linealidad yo prefiero llamarla continuidad, como la que define el concepto de Tradición Cultural, es para mi una hipótesis de trabajo de un libro (Lopez Mazz y Diego Bracco) que se llama "Notas y apuntes para la historia y la arqueología del territorio guenoa/minúan". En esta etapa se trató de reunir una base documental importante, que muestra la existencia de una identidad étnico-histórica guenoa/minuana específica y su distribución espacial entre los siglos XVII y XIX. En este último punto, Ilama la atención la coincidencia espacial entre la presencia 
minuana en el paisaje y las áreas anegadizas con presencia de cerritos de indios.

La hipótesis de continuidad entre pueblos constructores de cerritos y grupos guenoa/minúan, esta ya implícita en algunos trabajos clásicos de la Historiografía Riograndense como en los de Aurelio Porto. Itala Basile Becker y Juana Paris, sistematizan la información colonial, pero tengo la idea que no es ninguna sorpresa para los arqueólogos riograndenses veteranos (Schmitz, Naue, Mentz, Brochado, Copé). Donde es una sorpresa es en Uruguay, donde había un vacío de información entre la prehistoria y la guerra de los charrúas.

Además, la cultura material muestra continuidad en aspectos del subsistema tecnológico, al interior de un modo de producción esencialmente cazador de tierras bajas (y ecotono pampeano) a lo largo de miles de años. La arqueología de la muerte también ofrece algunas evidencias a favor de esa continuidad.

La pregunta es ¿por que una tradición arqueológica de más de 4 mil años y que llegó al siglo XVIII va a desaparecer sin dejar rastro? Acá lo que hay es un silencio político o una cuestión ignorada, propio del nivel de colonialidad de nuestras narrativas históricas nacionales. Por suerte la voluntad de descolonizarse comienza a cambiar nuestras universidades, Por otro lado, esa continuidad comienza a demostrarse con pruebas arqueológicas y pronto esperamos encontrar en el terreno, una toldería de algún gran cacique histórico minúan.

5) Aún a respecto de la arqueología de los Cerritos y de las poblaciones amerindias de la pampa, cuál el rumbo de sus investigaciones futuras?

Mi rumbo en este momento es el rumbo de los nuevos pesquisadores que aplican nuevos marcos teóricos, nuevas técnicas analíticas, producen fechados $\mathrm{C14}$, artículos y trabajos de post graduación sobre el tema. Estoy acompañando atentamente a los pequisadores que han hecho pos grado con el tema. Es mi trabajo, soy profesor universitario y orientador científico. Para las tierras bajas se ha mejorado mucho la reconstrucción paleoambiental, los estudios 
tecnológicos, los paleo económicos, los históricos, las secuencias radiocarbónicas, entre otras. La arqueología del sur de Brasil y Noreste de Uruguay esta avanzando mucho gracias al aporte de las nuevas generaciones.

En este momento trabajamos en el proyecto "El poblamiento temprano del este de Uruguay" (CSIC/UdelaR) que se orienta a estudiar el Pleistoceno Final pero sobretodo el Holoceno Temprano. Entre sus objetivos esta el de conocer mejor las sociedades cazadoras "arcaicas" del Holoceno Temprano (fachada Atlántica y lagunar) para entender los cambios que experimentan en el Holoceno Medio y que producen la emergencia progresiva de sociedades complejas a partir del $5 \mathrm{ka}$ a.P.

Se trata de dar un paso atrás, para mirar en perspectiva y en entre otras cosas, las innovaciones que traen los pueblos "constructores de cerritos". 